\title{
Thyroid Gland Lymphangioma
}

National Cancer Institute

\section{Source}

National Cancer Institute. Thyroid Gland Lymphangioma. NCI Thesaurus. Code C156345.

An extremely rare lymphangioma that arises from the thyroid gland. 